\title{
Good practices for prone positioning at the bedside: Construction of a care protocol
}

\author{
Vanessa Martins de Oliveira ${ }^{1 *}$, Michele Elisa Weschenfelder² ${ }^{2}$ Graciel Deponti ${ }^{3}$, Robledo Condessa ${ }^{3}$, Sergio Henrique Loss ${ }^{4}$, \\ Patrícia Maurello Bairros², Thais Hochegger², Rogério Daroncho², Bibiana Rubin ${ }^{5}$, Marcele Chisté2, Danusa Cassiana \\ Rigo Batista², Deise Maria Bassegio², Wagner da Silva Nauer ${ }^{3}$, Daniele Martins Piekala ${ }^{6}$, Silvia Daniela Minossi², \\ Vanessa Fumaco da Rosa dos Santos ${ }^{2}$, Josue Victorino ${ }^{7}$, Silvia Regina Rios Vieira ${ }^{8}$ \\ IMD - Intensive Care Unit, Coordinator of the Multidisciplinary Group of Teaching and Research in PRONE of the Hospital de Clínicas de Porto Alegre, Porto Aleore, RS, Brazil \\ 2Undergraduate Diploma Nurse at the Intensive Care Unit, HCPA, Porto Alegre, RS, Brazil \\ ${ }^{3} \mathrm{MSC}$ Physiotherapist at the Intensive Care Unit, HCPA, Porto Alegre, RS, Brazil \\ "PhD Intensive Care Physician and Nutrologist, HCPA, Porto Alegre, RS, Braz \\ 5Undergraduate Diploma Nutritionist at the Intensive Care Unit, HCPA, Porto Alegre, RS, Brazl \\ ${ }^{6}$ Undergraduate Diploma Physiotherapist at the Intensive Care Unit, HCPA, Porto Alegre, RS, Brazil \\ 'PhD Physician at the Intensive Care Unit, HCPA, Porto Alegre, RS, Brazil \\ PPhD Supervising Physician at the Intensive Care Unit, HCPA, Porto Alegre, RS, Brazl
}

Study conducted by the Grupo de Prona do Hospital de Clínicas de Porto Alegre (HCPA), Porto Alegre, RS, Brazi

Article received: $5 / 2 / 2015$ Accepted for publication: 12/1/2015

*Correspondence: Address: Rua Maranguape, 81/802, Petrópolis

Porto Alegre, RS - Brazi Postal code: $90690-380$ vanessa.oliveira480@gmail.com

http://dx.doi.org/10.1590/1806-9282.62.03.287

\section{SUMMARY}

Last year, interest in prone positioning to treat acute respiratory distress syndrome (ARDS) resurfaced with the demonstration of a reduction in mortality by a large randomized clinical trial. Reports in the literature suggest that the incidence of adverse events is significantly reduced with a team trained and experienced in the process. The objective of this review is to revisit the current evidence in the literature, discuss and propose the construction of a protocol of care for these patients. A search was performed on the main electronic databases: Medline, Lilacs and Cochrane Library. Prone positioning is increasingly used in daily practice, with properly trained staff and a well established care protocol are essencial.

Keywords: adult respiratory distress syndrome, acute respiratory distress syndrome, ventral decubitus, respiratory failure, intensive therapy.

\section{INTRODUCTION}

Prone positioning has been studied as a strategy for the treatment of acute respiratory distress syndrome (ARDS) since 1974, gaining popularity for improving hypoxemia in $70 \%$ of cases. ${ }^{1,2}$ The incidence of this syndrome has not changed in Europe over the last ten years and mortality remains high (40-50\%) despite technological and therapeutic developments in recent decades. ${ }^{3,4}$ The significant improvement of hypoxemia can be attested through numerous mechanisms, among which we can observe a more uniform distribution of transpulmonary pressure and the generation of more negative pleural pressures, promoting the improvement of the ventilation/perfusion ratio. ${ }^{5-10}$

Reduction in mortality with prone positioning is attributed to the lowest degree of pulmonary stress and strain, given that air distribution is more homogeneous and slower., ${ }^{90,12-15}$ The various meta-analyses in the literature to date concluded that there was an improvement in oxygenation, but no reduction in mortality. 16,17,19,26

The conflicting results of studies and meta-analyses, ${ }^{11,18,20-26,28}$ relating to mortality can be explained by the heterogeneity among patients regarding confusion factors such as the severity of the pulmonary injury, the ventilation strategy applied, and the different times for beginning and the duration of prone positioning. ${ }^{18}$

Therefore, Guerin et al. ${ }^{4}$ designed a randomized study (Proseva) with 466 patients with moderate ARDS in the first 12-24 hours of diagnosis, using a homogeneous sample of considerable size. All patients underwent protective mechanical ventilation, with the duration of prone positioning lasting on average 17 hours. This investigation demonstrated a significant reduction in mortality 
of $32.8 \%$, between 28 and 90 days, in the Supine group, and $16 \%$ in the Prone group, with a relative risk reduction of approximately $50 \%$, and $16 \%$ absolute risk reduction. Five years of training and experience of the team led to minimal complications.

Reports in the literature suggest that the incidence of adverse events is significantly reduced with a trained team, experienced in the process. . $^{4,910,27}$

By analyzing the studies, there are some important considerations for clinical practice concerning the mandatory use of protective mechanical ventilation, prolonged duration of prone positioning and the need for team training.

\section{Method}

The study method included search on the following electronic databases: Medline, Lilacs and Cochrane Library. Original research or systematic reviews were retrieved, without restrictions on language, including articles from 1995 to November 2, 2014. Studies that were excluded used patients younger than 18 years or investigations in animals.

The following MESH terms were used: ("prone position”[MeSH Terms]) OR Prone [TextWord]) OR prone[Text Word]) OR proning[Text Word])) AND (("Intensive Care"[Mesh]) OR "Intensive Care"[Text Word]) AND ("Respiratory Distress Syndrome, Adult"[MeSH Terms]) OR Respiratory Distress Syndrome, Adult[Text Word]) OR ARDS [Text Word]).

\section{LITERATURE REVIEW}

\section{Indications}

Patients who presented with moderate or severe ARDS with a $\mathrm{PaO}_{2} / \mathrm{FiO}_{2}$ ratio $\leq 150 \mathrm{mmHg}$, refractory hypoxemia (PEEP >10 $\mathrm{cmH}_{2} \mathrm{O}$ and $\mathrm{FiO}_{2}>60 \%$ ) in the first 1224 hours on protective mechanical ventilation (MV), and/ or difficulty in maintaining protective mechanical ventilation (alveolar distension pressure $\leq 15 \mathrm{cmH}_{2} \mathrm{O}$, plateau pressure $<30 \mathrm{cmH}_{2} \mathrm{O}, \mathrm{AFV}$ (air flow volume) of 4-6 $\mathrm{mL} / \mathrm{kg}$ of ideal weight and $\mathrm{pH}>7.15$ ), and/or those patients with right ventricular dysfunction (VD) on echocardiography. ${ }^{9,10,29,30}$

\section{Contraindications}

- Absolute contraindications: Hemodynamic instability (regarded as progressive elevation of the vasopressor), acute arrhythmia (need to reassess, when reversed or controlled), pregnancy (second or third trimester), face trauma or surgery, maxillofacial polytrauma (fracture of the pelvis, external fixation of fractures, rib or sternum fracture), intracranial hypertension, frequent convulsions, instability of the spine, abdominal com- partment syndrome, recent sternotomy, cardiac surgery, ophthalmic surgery (increased intraocular pressure) and recent abdominal surgery or intestinal ischemia.

- Relative contraindications: Bronchopleural fistula, hemoptysis/alveolar hemorrhage, recent tracheostomy (within the first 24 hours), significant abnormalities of the ribcage/kyphoscoliosis; high intra-abdominal pressure above $20 \mathrm{mmHg}$, without signs of compartmental syndrome and pregnancy (in the first trimester). $9,10,18,29,31$

\section{Start time and duration of prone positioning}

The biggest benefit of prone positioning occurs in the early stage of moderate or severe ARDS. Several studies have applied the position in the first 12-24 hours of early diagnosis of ARDS, after stabilization of symptoms. ${ }^{4,10,29,31}$

The duration of the position seems to be responsible for the reduction in mortality. ${ }^{4,13,14}$ A recent clinical trial has applied this procedure for 16-20 hours, with an average time of 17 hours and a significant reduction in the absolute risk (16\%) of death. ${ }^{4}$

Therefore, the current literature suggests that prone positioning should be performed in the first 12-24 hours of diagnosis of moderate or severe ARDS, after stabilization of the symptoms, and that the duration of the procedure must be no less than 16 hours.

\section{Response criteria to prone positioning}

Response to prone positioning should be assessed using blood gas tests collected after 2 hours of prone, and patients who have increases in the $\mathrm{PaO}_{2} / \mathrm{FiO}_{2}$ ratio of 20 $\mathrm{mmHg}$ or an increase in $\mathrm{PaO}_{2}>10 \mathrm{mmHg}$ compared with supine position are considered responsive., , $10,30^{-30}$

\section{Time for stopping prone positioning}

Recently, Guerin et al. ${ }^{4}$ suggest a daily re-evaluation of the need for the prone positioning. The procedure should be stopped when ventilation or complications improve.

\section{Ventilatory improvement}

- $\mathrm{PaO}_{2} / \mathrm{FiO}_{2}$ ratio $>150 \mathrm{mmHg}$ with $\mathrm{PEEP} \leq 10 \mathrm{cmH}_{2} \mathrm{O}$ and $\mathrm{FiO}_{2}<60 \%$ in supine position, for at least 4 hours after the end of the last prone session;

- decreased $\mathrm{PaO}_{2} / \mathrm{FiO}_{2}$ ratio greater than $20 \%$ in comparison to the supine position after two prone sessions.

\section{Complications}

- dislocation of the respiratory prosthesis;

- obstruction of the endotracheal tube, hemoptysis; 
- oxygen saturation less than $85 \%$ in pulse oximetry or $\mathrm{PaO}_{2}<55 \mathrm{mmHg}$ for more than 5 minutes with an $\mathrm{FiO}_{2}$ of 1.0;

- cardiorespiratory arrest;

- heart rate less than 30 beats per minute for more than 60 seconds;

- drop in systolic blood pressure greater than $60 \mathrm{mmHg}$ for more than 5 minutes;

- or any other life threatening situation., ${ }^{4,10,30}$

\section{Complications related to prone positioning}

The incidence of complications is low, at 3 per 1,000 patients/day. Pressure ulcers, pneumonia associated with mechanical ventilation and obstruction or decannulation of the endotracheal tube are the most common. Studies report that accidental extubation is a rare event $(0 \%$ to $2.4 \%){ }^{41,42}$ Complications can be minimized or prevented with monitoring and proper care. ${ }^{27,42,46}$

- Related to positioning: Pressure ulcers of the face, chest and knee; facial and chest edema; brachial plexus injury; surgical wound dehiscence; dietary intolerance and lack of flow of the hemodialysis catheter.

- Related to ETT: Accidental extubation; selective intubation; endotracheal tube displacement and obstruction of the endotracheal tube.

- Related to accesses: Removal of the hemodialysis catheter and other catheters; removal of enteral and vesical tubes. . $^{27,42,45,47}$

\section{PEEP titration}

There is clear guidance in the literature about PEEP, which must be maintained during and after prone positioning. The Brazilian Mechanical Ventilation Guideline strongly suggests maintaining standard PEEP prior to position. This titration can be done using the ARDSnet study's $\mathrm{FiO}_{2} \times$ PEEP table, ${ }^{32}$ or finding the ideal PEEP through the decremental PEEP maneuver.

\section{Use of neuromuscular blocker}

Recent studies and meta-analyses have demonstrated a reduction in mortality, no increased incidence of polyneuropathy in patients with moderate and severe ARDS $\left(\mathrm{PaO}_{2} / \mathrm{FiO}_{2}\right.$ ratio $\left.<120 \mathrm{mmHg}\right)$ under deep sedation using cisatracurium in the first 48 hours of ventilatory support. ${ }^{33-36}$

\section{Nutritional care during prone positioning}

Review articles, ${ }^{10}$ recommendation ${ }^{38}$ or consensuses ${ }^{30}$ on positioning of patients in prone do not to cite or are too summarized to report on how to nourish such individuals. ${ }^{37,39,40}$ This attests to the lack of uniformity in terms of the implementation of nutritional therapy among professionals, mainly in relation to the schedules of breaks during nutritional therapy. ${ }^{41}$

In a recent study, ${ }^{39}$ the use of a protocol based on the elevation of the patient's head (reverse Trendelemburg position), the use of fixed prokinetics and reduced speed of the diet allowed the application of early enteral nutrition and faster attainment of the planned energy target.

\section{Construction and implementation of the PROTOCOL}

Based on the above review of the literature the authors have implemented the following protocol in a tertiary university hospital (Figure 1).

\section{Nutritional CARE}

Before starting the diet, review the following precautions:

- Document the placement of the nasoenteric tube (NET) prior to placing the patient in the prone position based on abdominal $\mathrm{x}$-ray (if possible, the tube should be postpyloric, however, the gastric position does not contraindicate its use).

- Start diet with a semi-elemental formula after the first hour in prone position, using an infusion pump.

- Keep the head elevated at 25 degrees.

- Prescribe fixed prokinetics (metoclopramide, bromopride and erythromycin in isolation or combination).

- Check for the presence of food in the oral cavity or vomit every 2 hours.

- Pause the diet for 1 hour before replacing the patient in the supine position.

\section{In case of complications}

- Detection of food remnants in the oral cavity, vomiting or abdominal distension: suspend the diet, open the NET in a bottle and reassess restarting the diet in 3 hours. Restart the diet if the gastric residue is less than $250 \mathrm{~mL}$.

\section{Diet}

Choose a semi-elemental diet with the following progression:

- Formula $1 \mathrm{kcal} / \mathrm{mL}$ :

- hours 2 to 6 , flow $0.5 \mathrm{~mL} / \mathrm{kg} / \mathrm{h}$;

- hours 7 to 12 , flow $0.75 \mathrm{~mL} / \mathrm{kg} / \mathrm{h}$;

- hour 13 to the end, flow $1 \mathrm{~mL} / \mathrm{kg} / \mathrm{h}$;

- Formula $1.2 \mathrm{kcal} / \mathrm{mL}$ : 


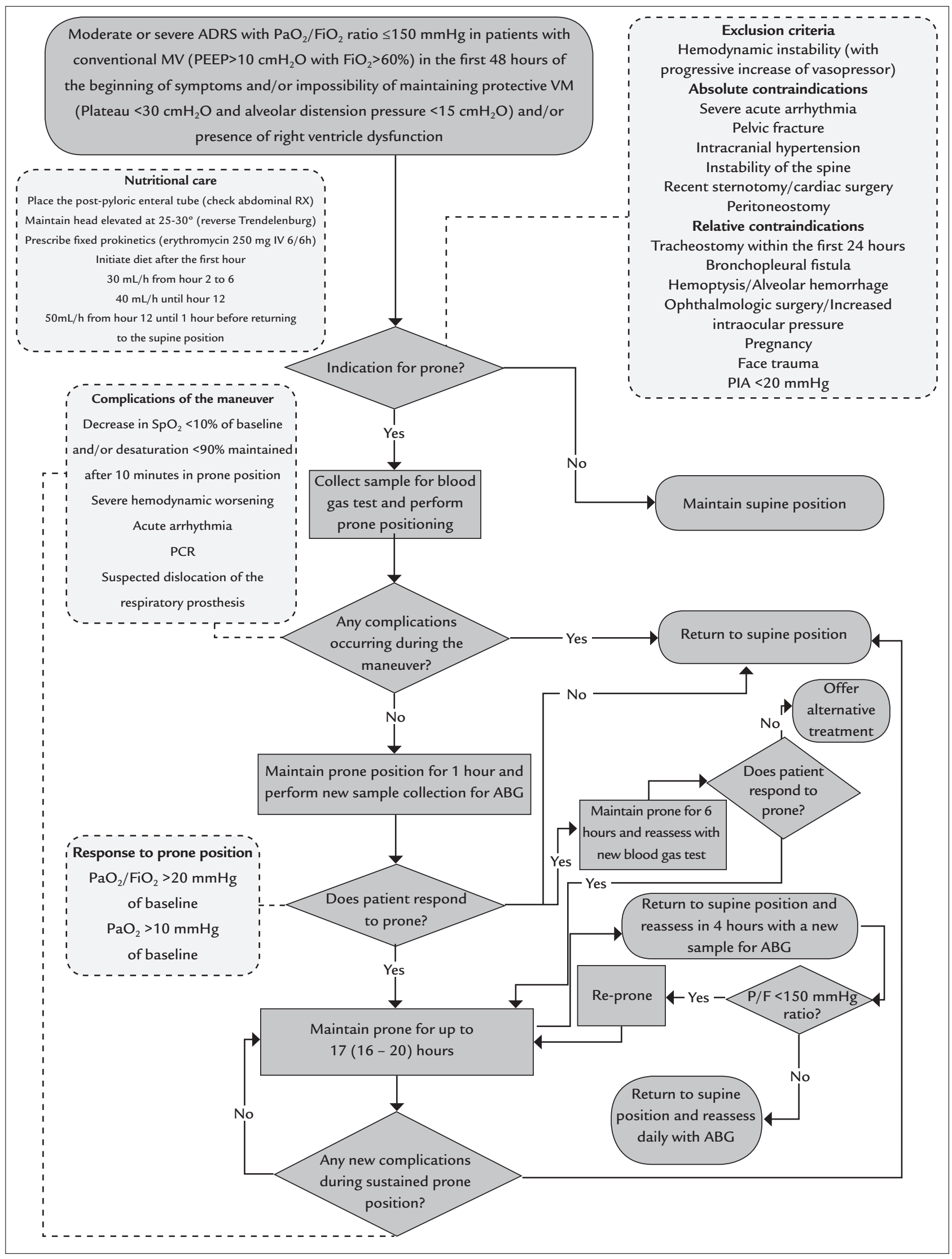

FIGURE 1 Protocol in a tertiary university hospital.

ABG: arterial blood gas. 
- hours 2 to 6 , flow $0.4 \mathrm{~mL} / \mathrm{kg} / \mathrm{h}$;

- hours 7 to 12 , flow $0.6 \mathrm{~mL} / \mathrm{kg} / \mathrm{h}$;

- hour 13 to the end, flow $0.8 \mathrm{~mL} / \mathrm{kg} / \mathrm{h}$;

- Formula $1.5 \mathrm{kcal} / \mathrm{mL}$ :

- hours 2 to 6 , flow $0.3 \mathrm{~mL} / \mathrm{kg} / \mathrm{h}$;

- hours 7 to 12 , flow $0.5 \mathrm{~mL} / \mathrm{kg} / \mathrm{h}$;

- hour 13 to the end, flow $0.65 \mathrm{~mL} / \mathrm{kg} / \mathrm{h}$;

- To simplify:

- 20 to $30 \mathrm{~mL} / \mathrm{h}$ from the $2^{\text {nd }}$ to the $6^{\text {th }}$ hour;

- $40 \mathrm{~mL} / \mathrm{h}$ until the $12^{\text {th }}$ hour;

- $50 \mathrm{~mL} / \mathrm{h}$ from the $12^{\text {th }}$ hour until 1 hour before returning to the supine position.

\section{NuRSING CARE IN THE HANDLING OF PRONE POSITIONING}

Care before performing prone position

Team

Pay attention to the need of a minimum of five people from the multidisciplinary team. Ensure the presence of a nurse, a physician and a physiotherapist. Determine the role of each team member prior to the start of the maneuver for prone positioning. The physician will be responsible for the head and endotracheal tube, and for coordinating the turn. It is important that this professional is present, as they will lead the maneuver at the headboard, where it will be possible to oversee the various devices. In the presence of a chest drain, a technician will be responsible for suspending the bottle. The other professionals should be placed two by two on each side of the bed. ${ }^{43,44}$

\section{Precautions}

Check the availability and proper functioning of the devices necessary for attending to the complications that may occur during the procedure. ${ }^{43,44}$

- Check the operation of the vacuum for suction of secretions, as well as the bag-valve mask device (AMBU) and urgent materials (intubation unit and crash cart). The crash cart should be positioned next to the patient's bed.

- Pay attention to the airway, checking the length of the lines of the mechanical ventilator and, if necessary, replacing the lines for longer ones.

- Remove the devices such as the oropharyngeal airway and the aspirators of the oral cavity.

- Guarantee the use of a closed suction system and the permeability of the endotracheal or tracheostomy, aspirating secretions, exchanging the fasteners, if necessary.

- Pay attention to the corners of the mouth and the cuff pressure.

- Pre-oxygenate the patient with $100 \% \mathrm{FiO}_{2}$ for 10 minutes.
- Eye (hygiene, hydration and ocular occlusion) and skin reinforcement (prevention and treatment of pressure ulcers using hydrocolloid dressings and local bony protuberances (chin, iliac crests and knees).

- Verify adequate fixation and the need to change the dressings of arterial and venous catheters, enteral and/ or gastric tubes and drains.

- Check the position of the nasoenteric tube by X-ray and auscultation, and suspend the diet 2 hours beforehand.

- Check the position of the infusion pumps, so that the equipment and the catheters are not tensioned during the procedure.

- Assess the need for increases in sedation and muscle relaxant.

Performing the prone position maneuver ${ }^{43,44}$

- In order to facilitate the movement, the bed should be positioned flat ( $0^{\circ}$ headboard elevation) and the patient's arms should be by the sides with the palms of the hands against the trunk.

- Pay attention to the clamping of the tubes and drains. Position them next to the patient's body on the moving sheet to avoid possible avulsions during the maneuver; the indwelling urinary catheter should be placed between the patient's legs on the moving sheet. In the presence of a chest drain, the bottle must be located below the patient's feet, with the drain positioned along its body.

- Remove the arterial line dome from the support, fixing it to the patient's body.

- Remove the electrodes from the anterior thorax and position on the upper limbs ( $\mathrm{V}$ in the anterior portion of the right shoulder, RA and RL in the anterior position of the right arm, LA and LL on the anterior portion of the left arm).

- Position of the cushions in supine position: Place a cushion measuring the width of the patient on the chest and another on the pelvis.

- Starting the envelope maneuver: Use the upper moving sheet, on top of the cushions, with the same arrangement as the lower one. Join the upper and lower moving sheets by the sides, winding the ends until they become tight and close to the patient's body, in order to proceed with the envelope maneuver.

- Move the patient, using the envelope made with both moving sheets, up to the side of the bed contrary to the side to which the turn will occur and the mechanical ventilator. In the case of chest tube, move to the side where you are inserting the drain, avoiding the spin- 
ning occurs about this, if necessary reposition the mechanical ventilator.

- Lateralize the patient carefully, at the command of the leading professional. Turn the patient into prone position, with cushions positioned below the chest and pelvis.

\section{Care and monitoring in prone position ${ }^{43,44}$}

- Bed in reverse Trendelemburg position $\left(25^{\circ} 30^{\circ}\right)$.

- Check the placement of the endotracheal tube.

- Reposition the dome of the arterial line on the support, adjusting the level and resetting.

- Check the correct positioning of the chest and pelvis cushions (the abdomen should be free).

\section{Electrodes on the back and swimmer position ${ }^{43,44}$}

- Fix the electrodes on the arms on the back of the patient correctly; (in the revers RA and RL position on the posterior thorax to the right of the patient and LA and LL on the posterior thorax to the left of the patient).

- Place the patient in "the swimmer position": One of the limbs should be raised to $80^{\circ}$ of abduction with the elbow flexed at $90^{\circ}$, the face should be turned to the raised limb, and the other arm should remain at the side of the body.

- Alternate the side of the swimmer position every 2 hours.

- Position the circular cushion under the patient's face, avoiding facial injuries, and a cushion on the palm of the hand of the raised limb, extending the fist and maintaining the flexion of the fingers. Put a cushion below the region of the knees, on the anterior portion of the legs in order to keep the ankles in neutral position.

- Unclamp and check the tubes and drain.

- Perform monitoring and relief of pressure points on bony protuberances while in ventral position.

- Assess the resumption of enteral diet after 1 hour in the prone position and monitor the presence of abdominal distension.

\section{Return to the supine position}

Return to supine positioning should consider the same precautions performed in prone. ${ }^{43,44}$

\section{Final considerations}

It is likely for prone positioning to be increasingly used in daily practice, being essential a properly trained team and a well-established care protocol in order to make the position a safe technique.

\section{Resumo}

Boas práticas da manobra de prona à beira do leito: construção de um protocolo de cuidados

No último ano, o interesse pela posição prona no tratamento da síndrome da angústia respiratória aguda (Sara) ressurgiu com a demonstração da redução da mortalidade por um grande estudo clínico randomizado. Os relatos, na literatura, sugerem que a incidência de eventos adversos é significativamente reduzida com uma equipe treinada e experiente no processo. O objetivo desta revisão é revisitar as evidências atuais, discutir e propor a construção de um protocolo de cuidados para esses pacientes. Foi realizada busca nas principais bases eletrônicas: Medline, Lilacs e Cochrane Library. A posição prona é cada vez mais utilizada na prática diária, sendo imprescindível a presença de uma equipe adequadamente treinada e um protocolo de cuidados bem estabelecido.

Palavras-chave: síndrome do desconforto respiratório do adulto, síndrome da angústia respiratória aguda, decúbito ventral, insuficiência respiratória, terapia intensiva.

\section{References}

1. Bryan AC. Conference on the scientific basis of respiratory therapy. Pulmonary physiotherapy in the pediatric age group. Comments of a devil's advocate. Am Rev Respir Dis. 1974; 110(6 Pt 2):143-4.

2. Taccone P, Pesenti A, Latini R, Polli F, Vagginelli F, Mietto C, et al. ProneSupine II Study Group. Prone positioning in patients with moderate and severe acute respiratory distress syndrome: a randomized controlled trial. JAMA. 2009; 302(18):1977-84.

3. Villar J, Sultemanji D, Kacmarek RM. The acute respiratory distress syndrome: incidence and mortality, has it changed? Curr Opin Crit Care. 2014; 20(1):3-9.

4. Guérin C, Reignier J, Richard JC, Beuret P, Gacouin A, Boulain T, et al PROSEVA Study Group. Prone positioning in severe acute respiratory distress syndrome. N Engl J Med. 2013; 368:2159-68.

5. Suarez Sipmann F, Bohm SH. Recruit the lung before titrating the right positive end-expiratory pressure to protect it. Crit Care. 2009; 13(3):134

6. Ranieri VM, Brienza N, Santostasi S, Puntillo F, Mascia L, Vitale N, et al Impairment of lung and chest wall mechanics in patients with acute respiratory distress syndrome: role of abdominal distension. Am J Respir Crit Care Med. 1997; 156(4 Pt 1):1082-91.

7. Paiva KCL, Beppu OS. Posição prona. J Bras Pneumol. 2005; 31(4):332-40,

8. Marini J, Rubenfeld G. Pro/con clinical debate: The use of prone positioning in the management of patients with acute respiratory distress syndrome. Crit Care. 2002; 6(1):15-7.

9. Guérin C. Prone position. Curr Opin Crit Care. 2014; 20(1):92-7.

10. Gattinoni L, Taccone P, Carlesso E, Marini JJ. Prone position in acute respiratory distress syndrome. Rationale, indications, and limits. Am J Respir Crit Care Med. 2013; 188(11):1286-93.

11. Gattinoni L, Tognoni G, Pesenti A, Taccone P, Mascheroni D, Labarta V, et al. Effect of prone positioning on the survival of patients with acute respiratory failure. N Engl J Med. 2001; 345(8):568-73.

12. Guerin C, Gaillard S, Lemasson S, Ayzac L, Girard R, Beuret P, et al. Effects of systematic prone positioning in hypoxemic acute respiratory failure: a randomized controlled trial. JAMA. 2004; 292(19):2379-87,. 
13. Mancebo J, Fernández R, Blanch L, Rialp G, Gordo F, Ferrer M, et al. A multicenter trial of prolonged prone ventilation in severe acute respiratory distress syndrome.. Am J Respir Crit Care Med. 2006; 173(11):1233-9.

14. Taccone P, Polli F, Gattinoni L. Prone positioning in patients with acute respiratory distress syndrome - Reply. JAMA. 2010; 303(9):832-3.

15. Beitler JR, Shaefi S, Montesi SB, Devlin A, Loring SH, Talmor D, et al. Prone positioning reduces mortality from acute respiratory distress syndrome in the low tidal volume era: a meta-analysis. Intensive Care Med. 2014; 40(3):332-41.

16. Sud S, Friedrich JO, Taccone P, Polli F, Adhikari NK, Latini R, et al. Prone ventilation reduces mortality in patients with acute respiratory failure and severe hypoxemia: systematic review and meta-analysis. Intensive Care Med. 2010; 36(4):585-99.

17. Abroug F, Ouanes-Besbes L, Elatrous S, Brochard L. The effect of prone positioning in acute respiratory distress syndrome or acute lung injury: a meta-analysis. Areas of uncertainty and recommendations for research. Intensive Care Med. 2008; 34(6):1002-11.

18. Dickinson S, Park PK, Napolitano LN. Prone positioning therapy in ARDS Crit Care Clin. 2011; 27(3):511-23.

19. Abroug F, Ouanes-Besbes L, Dachraoui F, Ouanes I, Brochard L. An updated study-level meta-analysis of randomised controlled trials on proning in ARDS and acute lung injury. Crit Care. 2011; 15(1):R6.

20. Alsaghir AH, Martin CM. Effect of prone positioning in patients with acute respiratory distress syndrome: a meta-analysis. Crit Care Med. 2008;36(2):603-9.

21. Cesana BM, Antonelli P, Chiumello D, Gattinoni L. Positive end-expiratory pressure, prone positioning, and activated protein C: a critical review of meta-analyses. Minerva Anestesiol. 2010; 76(11):929-36.

22. Kopterides P, Siempos I.I, Armaganidis A. Prone positioning in hypoxemic respiratory failure: meta-analysis of randomized controlled trials. J Crit Care. 2009; 24(1):89-100.

23. Phua J, Badia JR, Adhikari NK, Friedrich JO, Fowler RA, Singh JM, et al. Has mortality from acute respiratory distress syndrome decreased over time? A systematic review. Am J Respir Crit Care Med. 2009; 179(3):220-7.

24. Putensen C, Theuerkauf N, Zinserling J, Wrigge H, Pelosi P. Meta-analysis: ventilation strategies and outcomes of the acute respiratory distress syndrome and acute lung injury. Ann Intern Med. 2009; 151(8):566-76

25. Sud S, Sud M, Friedrich JO, Adhikari NK.. Effect of mechanical ventilation in the prone position on clinical outcomes in patients with acute hypoxemic respiratory failure: a systematic review and meta-analysis. CMAJ. 2008; 178(9):1153-61.

26. Tiruvoipati R, Bangash M, Manktelow B, Peek GJ. Efficacy of prone ventilation in adult patients with acute respiratory failure: a meta-analysis. J Crit Care. 2008; 23(1):101-10.

27. Lee JM, Bae W, Lee YJ, Cho YJ. The efficacy and safety of prone positional ventilation in acute respiratory distress syndrome: updated study-level meta-analysis of 11 randomized controlled trials. Crit Care Med. 2014; 42(5):1252-62.

28. Sud S, Friedrich JO, Adhikari NK, Taccone P, Mancebo J, Polli F, et al. Effect of prone positioning during mechanical ventilation on mortality among patients with acute respiratory distress syndrome: a systematic review and meta-analysis. CMAJ. 2014; 186(10):E381-90.

29. Athota KP, Millar D, Branson RD, Tsuei BJ. A practical approach to the use of prone therapy in acute respiratory distress syndrome. Expert Rev Respir Med. 2014; 8(4):453-63.
30. Diretrizes brasileiras de ventilação mecânica. Realização: Associação de Medicina Intensiva Brasileira (AMIB) - Comitê de Ventilação Mecânica e Sociedade Brasileira de Pneumologia e Tisiologia (SBPT) - Comissão de Terapia Intensiva da SBPT, 2013.

31. Marini JJ. Prone positioning for ARDS: defining the target. Intensive Care Med. 2010; 36(4):559-61.

32. The Acute Respiratory Distress Syndrome Network. Ventilation with lower tidal volumes as compared with traditional tidal volume for acute lung injury and the acute respiratory distress syndrome. N Engl J Med. 2000; 342(18):1301-8.

33. Alhazzani W, Alshahrani M, Jaeschke R, Forel JM, Papazian L, Sevransky J, et al. Neuromuscular blocking agents in acute respiratory distress syndrome: a systematic review and meta-analysis of randomized controlled trials. Crit Care. 2013; 17(2):R43.

34. Needham, CJ Brindley PG. Best evidence in critical care medicine: the role of neuromuscular blocking drugs in early severe acute respiratory distress syndrome. Can J Anaesth. 2012; 59(1):105-8.

35. Hraiech S, Forel JM, Papazian L. The role of neuromuscular blockers in ARDS: benefits and risks. Curr Opin Crit Care. 2012; 18(5):495-502.

36. Papazian L, Forel JM, Gacouin A, Penot Ragon C, Perrin G, Loundou A, et al. ACURASYS Study Investigators. Neuromuscular blockers in early acute respiratory distress syndrome. N Engl J Med. 2010; 363(12):1107-16.

37. Reignier J, Vinatier I, Martin-Lefevre L, Clementi E, Fiancette M. Nutrition entérale et ventilation mécanique en décubitus ventral. Réanimation. 2010; 19(5):454-9.

38. Reignier J, Thenoz-Jost N, Fiancette M, Legendre E, Lebert C, Bontemps F, et al. Early enteral nutrition in mechanically ventilated patients in the prone position. Crit Care Med. 2004; 32(1):94-9.

39. Reignier J, Dimet J, Martin-Lefevre L, Bontemps F, Fiancette M, Clementi E, et al. Before-after study of a standardized ICU protocol for early enteral feeding in patients turned in the prone position. Clin Nutr. 2010; 29(2):210-6.

40. Van der Voort PHJ, Zandstra D. Enteral feeding in the critically ill: comparison between the supine and prone positions: a prospective crossover study in the mechanically ventilated patients. Crit Care. 2001; 5(4):216-20

41. Schneider JA, Lee YJ, Grubb WR, Denny J, Hunter C. Institutional practices of withholding enteral feeding from intubated patients. Crit Care Med. 2009; 37(7):299-302.

42. Ball C, Adams J, Boyce S, Robinson P. Clinical guidelines for the use of the prone position in acute respiratory distress syndrome. Intensive Crit Care Nurs. 2001; 17(2):94-104.

43. Marion BS. A turn for the better: prone positioning of patients with ARDS Am J Nurs. 2001; 101(5):26-34; quiz 34-5.

44. Dirkes S, Dickinson S, Havey R, O'brien D. Prone positioning: is it safe and effective? Crit Care Nurs Q. 2012; 35(1):64-75.

45. Rowe C. Development of clinical guidelines for prone positioning in critically ill adults. Nurs Crit Care. 2004; 9(2):50-7.

46. Girard R, Baboi L, Ayzac L, Richard JC, Guerin C; Proseva trial group. The impact of patient positioning on pressure ulcers in patients with severe ARDS: results from a multicentre randomised controlled trial on prone positioning. Intensive Care Med. 2014; 40(3):397-403.

47. Wright AD, Flynn M. Using the prone position for ventilated patients with respiratory failure: a review. Nurs Crit Care. 2011; 16(1):19-27. 